\title{
Working a Whistler
}

\section{A Dangerous Task That Requires Skill}

\author{
By C. H. Claudy
}

SEA-TRAVELERS up and down our coast lines Soften hear a strange, weird sound to port or starboard, a sort of compound of moan and shriek, at once soft and insistent, subdued and penetrating. It is the call of the whistling buoy to the man at the helm, warning him of shoal or dangerous place, giving him his bearings, by.which he may steer his vessel in safe water.

These whistling buoys, which are enormous masses of iron, often weighing several tons, are as simple in principle as they are certain in operation. The buoy proper consists of a huge pear-shaped bulb, little end up, on top of which is a powerful whistle, protected from accidental blow or collision by a framwork of iron bars, and an air intake. Below and projecting far down into the water is an open tube of metal. The whole thing is secured in position with an anchor and a chain, which last is long enough for the depth of the water in which the buoy is placed, to permit the free movement of the mass up and down.

When a wave lifts the buoy up in the air, the water left there for an indefinite period of time. But the sea has strange ways with her playthings, and, even if the necessity of constant painting of the buoy to protect it from the action of sea water was not existent, it would still be necessary to keep a watch on these signals, and to take them up and replace them rather often. For the big tube projecting down into the water is a great attraction to barnacles and sea weed, and not infrequently these marine growths so interfere with the action of the buoy as to keep it silent in ordinary weather and to dim its voice in bad weather.

It then becomes necessary to "work" a new whistler in position, which is a regular part of the duty of a lighthouse tender or buoy tender, of which vessels there are many in the Lighthouse Service.

When a buoy is to be "worked" the tender repairs to a yard or station, and by means of her crane, lifts on deck the freshly painted and thoroughly repaired new buoy, which is to replace that one which is either silent or which has served its allotted time and is now due for replacement. anchor and chain tossed after it, the unusual spectacle is presented of two whistling buoys, side by side. But the new buoy is silent

"Lazy-doesn't want to work," say the sailors. But it is only waiting until the water has filled its long tube to take up the burden of its mournful song-a sound so indescribably melancholy that the department has always scores of protests from land dwellers when one of these sirens is placed within sounding position. buoy overboard is dangerous work, hauling the old one in is more so. The buoy is first secured by good seamanship, managing the steam vessel, with a rope through the iron cage at its top. Working from this, ropes, chains and "springs" or heavy cables are brought into play and the whole very cautiously lifted and secured as it comes over the side It is allowed to swing free not at all, save perhaps for an instant, just as it is laid flat on the deck, and then, apparently in the very face of death, a dozen men spring at the mass, ready to swing with the waves and to demolish them, and thrust. huge billets of wood

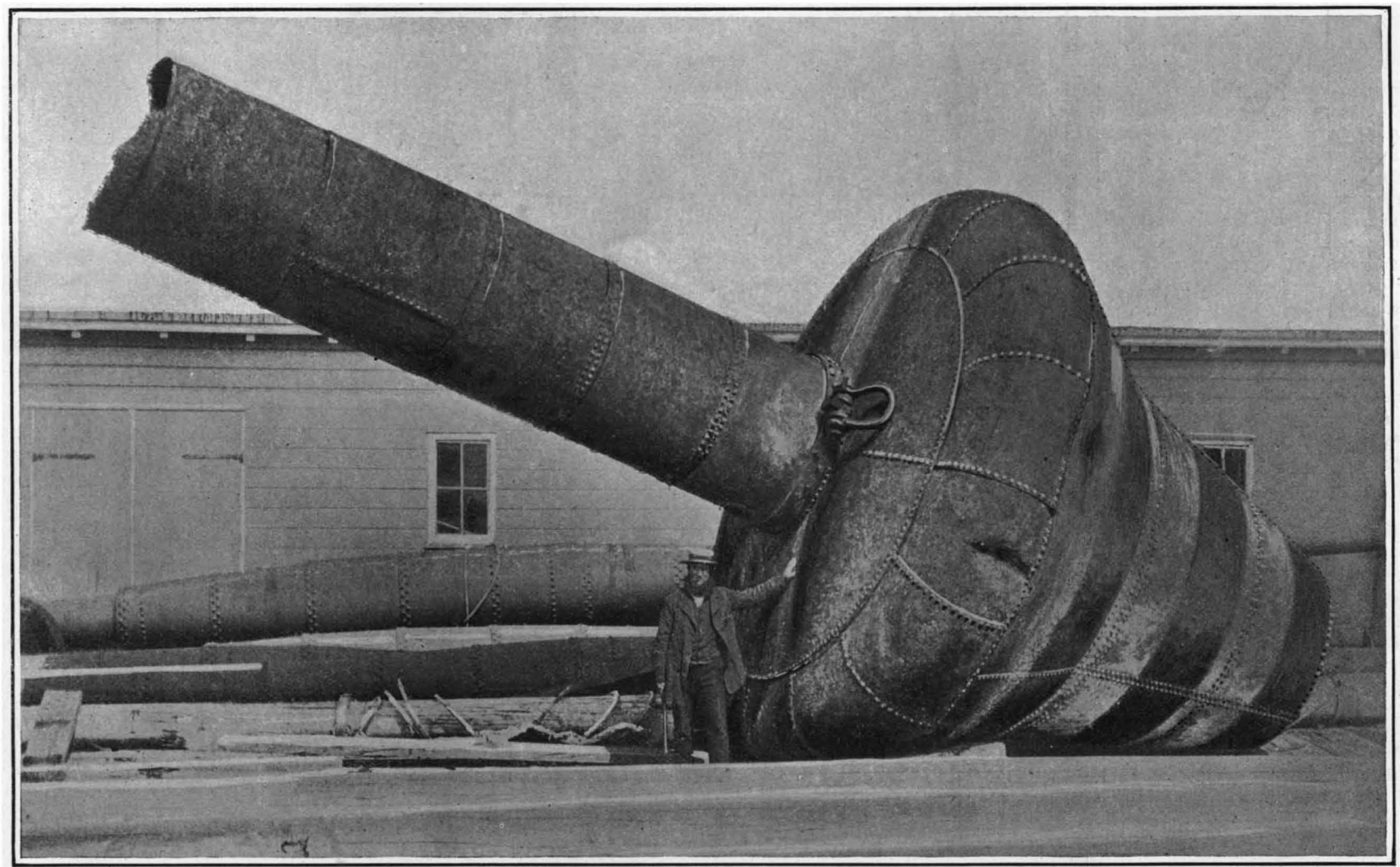

A monster whistling buoy, which has been damaged by being struck by an ocean liner. Tube cut in half by propeller blow.

in the tube, acting as a piston, sucks in air through the intake. It is confined in the bulb of the buoy by a simple valve which prevents its egress through the When the waves drop the buoy in the tr of the waves, the water in the tube presses up on the confined air and compresses it. It finds exit through the whistle, which thus sounds its warning note.

Whistling buoys are only placed in water where the wave action is fairly eonstant, so that calms and fair weather will not stop the action of the buoy any more than can be hel the buoy is less needed in fair weather than in foul, and that it takes comparatively little disturbance of the water to make the buoy sound its warning. The higher the waves, of course the louder the sound.

There are eighty-eight of these buoys at present in service in this country, and twenty-five whistling buoys which are also light buoys, showing a visible signa at night. They differ in size from the small one used in harbors and where the sound need not be very powerful in order to reach as far as may be necessary, to the huge masses of iron which are given to the wate as a plaything at the entrance to harbors or whereve a shoal needs a warning signal which cannot, or for

It might be supposed that, having no mechanism but a valve, such buoys, once put in position, could be
There is nothing difficult about this; it is getting the enormously large and unwieldy mass of iron orerboard and taking on board the one which is in the water, which causes the difficulty. The very waves which are necessary to the successful operation of the buoy make it hard to manage at the end of a crane on board a comparatively small vessel.

When a buoy tender goes to "work" a whistler she clears her deck of everything else but the buoy, which is secured with chock The old buos is approached cautiously, within a couple of hundred feet, and the new buoy is allowed to slide overboard, rather than picked up and placed in the water, the crew guiding it by guy ropes while the powerful crane lifts just enough to permit the buoy to move. With the vessel slowly rolling from side to side on the slow seas of even a quiet day-the good days are purposely picked for this work-the mass of freshly painted iron with its long tube presents potentialities for evil which must be closely watched. Let the buoy but get clear of the deck and the fall tackle get jammed, and there would come into being a three-ton pendulum with an iron flail, thirty-six feet long, capable of smashing the boat to bits and certainly of sweeping broken-boned men about the deck with no more effort than if they were so many flies.

When the new buoy is safely into the water and its underneath its sides, to hold it long enough for lashings to make it secure. The boat, being belayed to the anchor chain, then cautiously backs away to raise the anchor, perhaps buried for months in the mud, and there is a general scampering away from the cable while this is being done, as should it break it would be like having a couple of cannon balls come tearing along the deck; a breaking two-inch cable is as rigid as an iron bar and with hundreds of tons of force in its swift flick through space.

However, so skillful are these handlers of heavy masses of iron on an unstable keel, that it is rare that an accident happens, while most of those which occur to whistling buoys are caused either by their being run down and their tubes cut off $\cdot$ by the propellers of large vessels or by their being damaged by ice.

\section{Rope Shoes for Horses}

IN Germany many horses are being shod with shoes made of tarred rope. The object is to prevent slipping on streets covered with asphalt or paved blocks. In some of these shoes there is also a block of wood, into which stiff bristles have been driven. This is an additional preventive against slipping, and strengthen the shoe. They are light and comfortable for the horse, and deaden the sound of the hoof. 
$\mathrm{R}$ EADERS are invited to contribute to $\mathbf{R}_{\text {this department photographs of nove }}$ and curious objects, unique occurrences, and ingemious contrivances Such as are available will be paid for promptly.

\section{Aeroplane Vans for the French Army}

C OME time ago we called attention to $S$ the horse-drawn vans that were being used by the French army for the transportation of aeroplanes. The French War Department is now making use of automobiles for this purpose, and our illustration shows a number of motor vans with their trailers used for the transportation of an esquadrille of aeroplanes. The aeroplanes are dismounted and placed in the trailers, and the motor van is used for the transportation of spare parts, etc Each esquadrille, consisting of from six to eight aeroplanes, has a couple of machineshop repair trucks such as we illustrated a few weeks ago. These trucks have sides which open and form work benches, while they are fitted with all the necessary lathes and machine tools used for the repairing of aeroplanes. The new motor transport vans effect a great saving of time in the moving of aeroplanes from when it is not desired to send them by the air route.

\section{A Violin Made of Matches}

THERE are certain individuals, who 1 have a penchant for putting to curious use, materials that others consider worthless. Thus a man will make a clock out of bits of straw or a cane out of old newspapers. Here is a picture of a violin the body of which was built of matches. A man living in Bay City, Wisconsin, conceived the novel idea, and spent a year in the: painstaking operation of constructing a musical instrument out of the refuse of the match-box. "The instrument contains 5,450 matches," says the man wh sent us the photograph, and he also as sures us that the violin has "a full, sweet, mellow tone," which, if really so, strikes us as even more remarkable than its peculiar construction. The instrument has been on exhibition at the Minnesota State Fair, where it attracted a great deal of attention.

The Acme of Car Luxury

$\mathbf{N}$ order to travel with all the conveniences of the twentieth century, and even to dine in privacy en route without be ing compelled to leave her car, a Germa singer of note has ordered a traveling limousine which must be considered the acme of luxury. As the illustration shows, it can be converted into a dining room, com pletely and luxuriously fitted By a few deft touches it can be transformed into a "boudoir," card-room or bedroom. Th seats are adjustable so as to form a broad and comfortable davenport bed.

\section{Girdling Orange Trees}

PICTURED herewith is a Washingto navel orange weighing $3 \frac{1}{4}$ pounds and measuring 18 inches in circumference, which was grown by Mr. Robert Howe in Orlando, Florida, in 1892. Beside this giant specimen may be seen a kumquat and a nonpareil. Mr. Howe had a number : of Washington navel trees, which bloomed more profusely than any 'othe variety, but would not hold their -fruit producing an average of one box per tree. In the spring of 1892 , just when the'fruit began to appear he girdled the trees, taking ant:a strip of the bark about $1 / 8$.inch wide. The result was a yield of from eight to ten boxes per tree, while a large majority of the oranges were of an enormous size, but thin-skinned and full of juice. Some of the largest were displayed in the "Florida on Wheels" exhibit, a car loaded with Florida products that ran all over sthe Northern . States. The trees weres gindud iagain the next. two years and gave a full crop, but the fruit was all of medium size. In February, 1895, a the trees were killed by frost. . Grape rines, apple trees and the like are some-

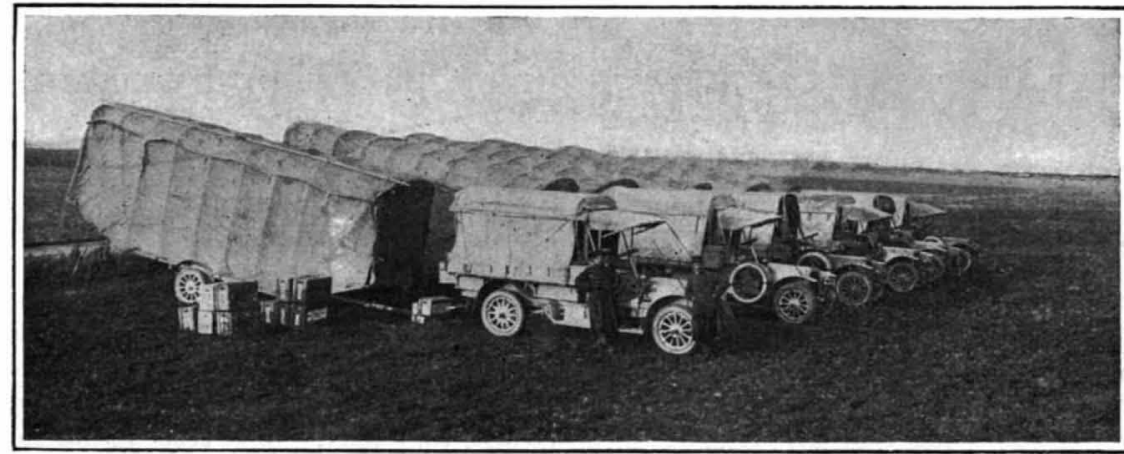

Motor vans and trailers for French army aeroplanes.

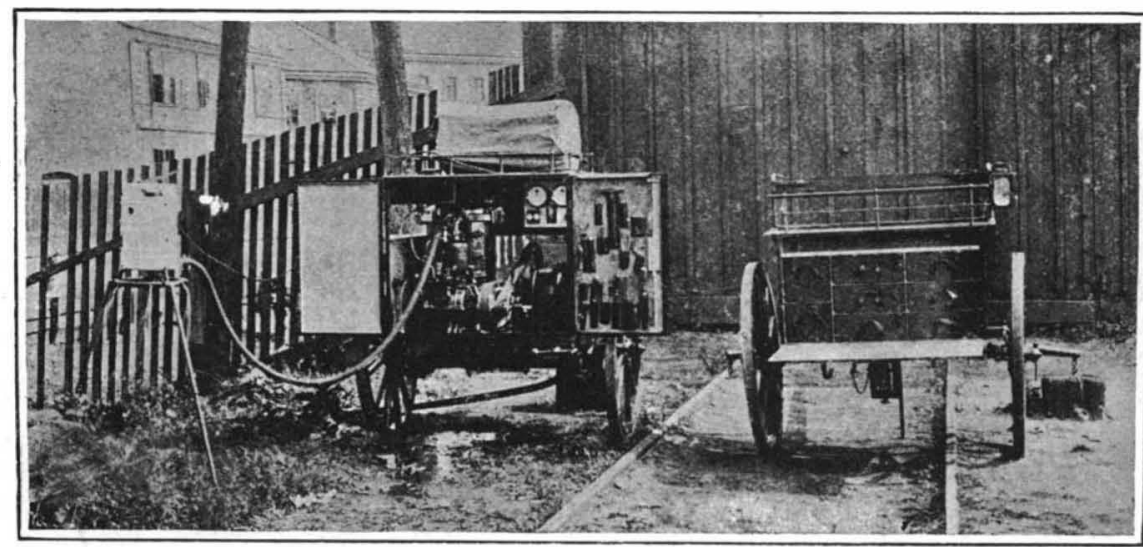

Austrian army ultra-violet sterilizer filling a water tank.

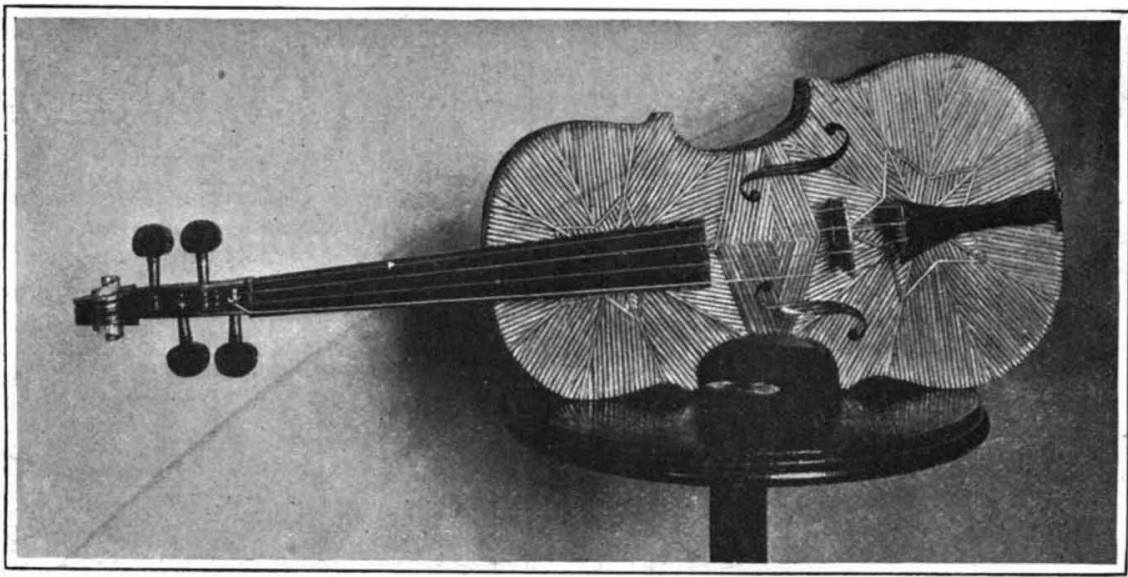

A violin built of 5,450 matches.

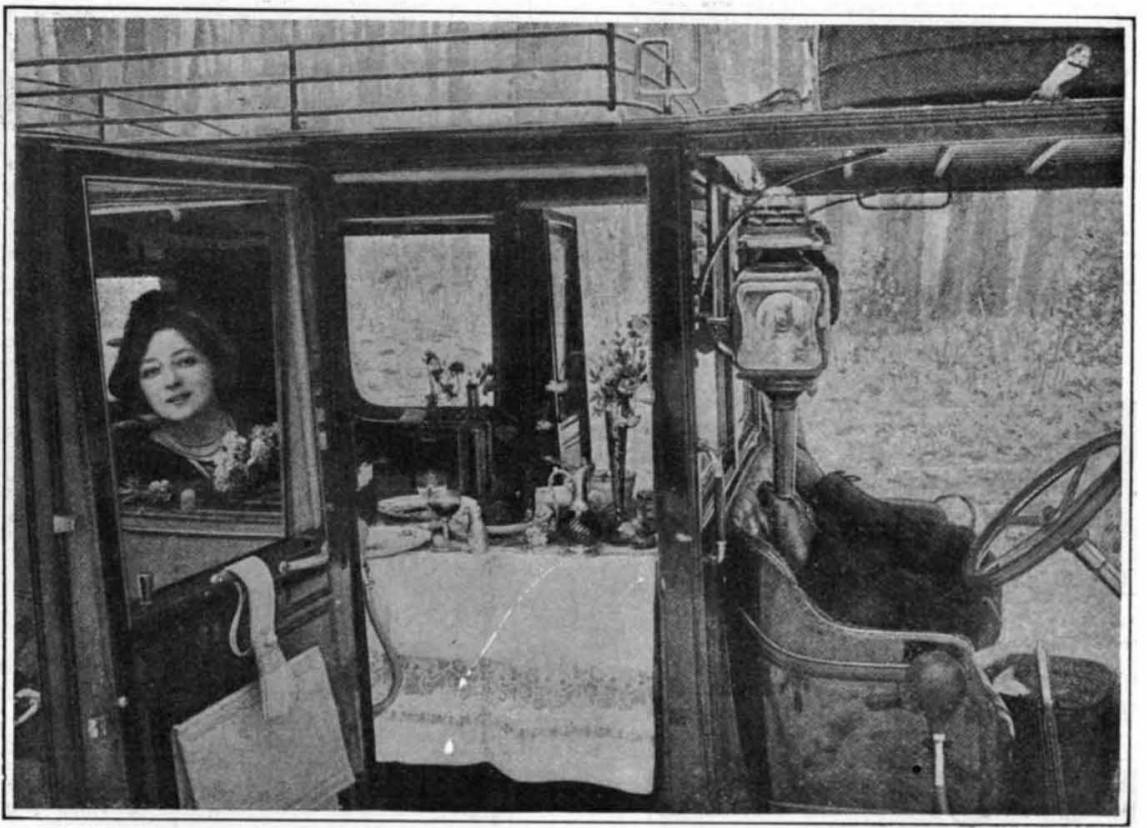

A limousine converted into a dining car.

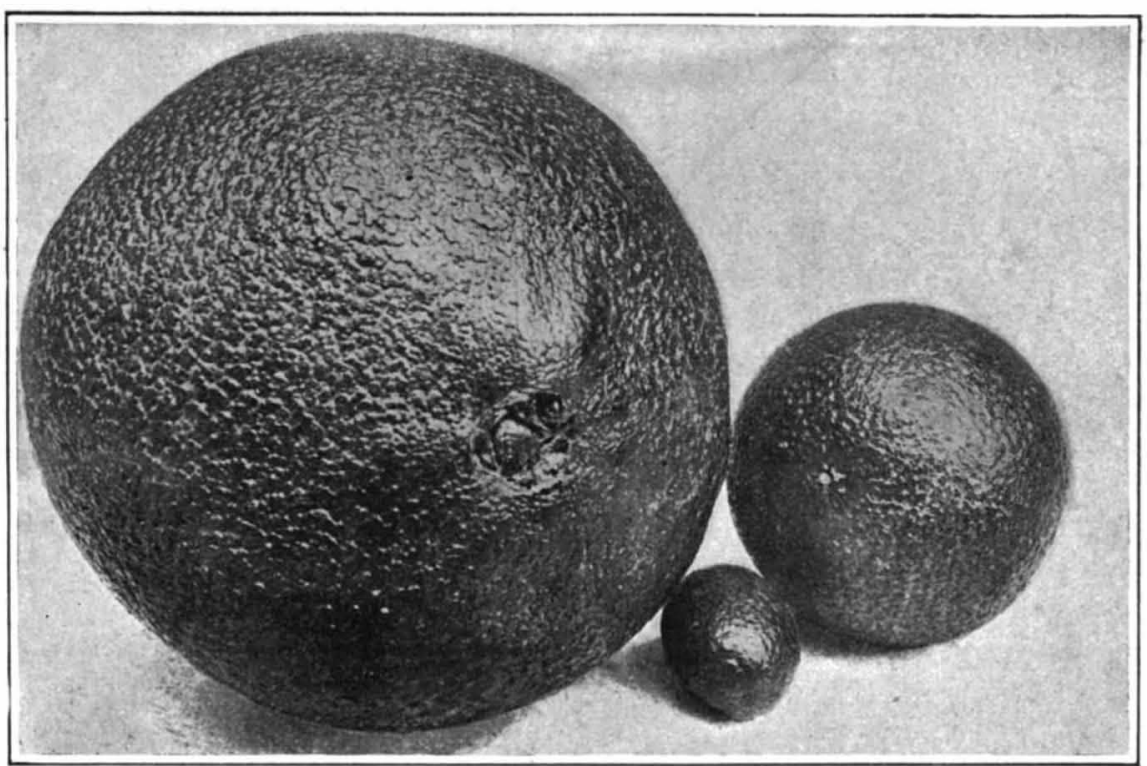

Giant orange produced by girdling, compared with a nonpareil and a kumquat. times girdled to obtain larger fruit, but this is usually attended by a diminution of the quantity of the yield. Such was apparently the case with Mr. Howe's orange trees; for as the size of the fruit diminished in successive years the quantity increased.

Ultra-violet Light Sterilizer for the Austrian Army

THE new French ultra-violet ray water 1 purifying apparatus has been made up in portable form and is now being tried out by the Austrian army upon its first trials. As the apparatus is intended to be used for a supply of pure drinking water for troops in the field, it is a complete plant, containing its own machines for operating pumps and producing electric current so that it can be set up at any point on the field. When on the road the small front truck containing the driver's seat and also a supply box is attached to the apparatus proper, which is mounted in the rear box upon a twowheeled truck. When on the spot, the rear box is detached and opened up, and the sterilizing tank removed and set up on a tripod support so as to be within easy reach of the troops. Within the case is a well-designed plant consisting of a small gasoline engine coupled to a rotary pump and also to a dynamo. A hose leads from the pump to the source of water supply, such as a well or pond, and the water is pumped up and sent directly into water is pumped or if not it passes first through a rapid or if not it passes first through a rapid filter. A short piece of hose connects the plant to the sterilizer, and electric wires also make connection with the dynamo so as to supply the mercury vapor lamp. A set of instruments serve to give the proper amount of electric current, and automatic devices cut off the current when the water is not fiowing out of the tank, in which case automatic valves also stop the water supply from the pump. The present apparatus is likely to be valuable in keeping up the good health of the troops, as when on the field the water is often taken from polluted sources, and this is recognized to be one of the main causes of disease. Researches made at the laboratories of the Paris University by Prof. V. Henri show that provided it is so clear as not to prevent the ultraviolet rays from penetrating below the surface, water which is heavily charged with coli bacillus and other most dangerous microbes, is rendered quite harmless. Such microbes are, in fact, entirely destroyed by the powerful action of the rays, as is shown by numerous analysis.

\section{Artificial Marble}

THE artificial, or stucco, marble is in the main part composed of gypsum, which should be hard, so that the product can be smoothed and polished. To the finely powdered and sieved burnt gypsum marble dust is often added and the mixture gaged with water in which mucilage has been dissolved. The colors and the streaks or veins, the able imitation of which is the main object in the manufacture of artiflcial marble, are added to the dry mixture, as mineral colors, or during the hardening of the finished product upon its surface by aid of chemical compositions.

To obtain streaked slabs large balls of gypsum are kneaded with smaller ones of different colors, and from the ball so obtained thin slabs are cut, which are laid upon the still damp base and then subjected to high pressure. After hardening the slabs are planed. To avoid this toilsome operation of planing, a sheet of glass, highly polished and rubbed with oil, is used. Colored lines representing the veins are traced upon this sheet; then a $8 / 1$-inch layer of a thick mixture of gypsum of the desired color is carefully poured over the glass and left to harden. After hardening the slab is carefully removed, and the surface next to the glass will be found to be absolutely smooth, and need no planing. 